\title{
Arbor
}

\section{El Patrimonio Nacional. Museos vividos}

José G. Moya Valgañón

Arbor CLXIX, 665 (Mayo 2001), 15-28 pp.

El Patrimonio Nacional, según queda definido en las disposiciones vigentes (Ley 23/1982 de 16 de junio y su Reglamento aprobado por Real Decreto 4960/1987 del 18 de marzo), es un conjunto de bienes de titularidad estatal afectadas al uso y servicio del Rey y de los miembros de la Familia Real para el ejercicio de la alta representación que la Constitución y las leyes les atribuyen. Además se integran en él los derechos y cargas de Patronato sobre las Fundaciones y Reales Patronatos a que se refiere dicha Ley. La citada legislación señala, en su artículo primero, que se gestiona y administra por un Consejo de Administración el cual, según el artículo tercero, adoptará las medidas conducentes al uso de tales bienes con fines culturales, científicos y docentes, en tanto en cuanto ello sea compatible con el uso antes aludido.

Es conveniente, a mi juicio, que comience mi exposición por esta especie de declaración de principios que es la definición legal del $\mathrm{Pa}$ trimonio, porque veremos que se trata de un mundo muy distinto al que, habitualmente, están acostumbrados buena parte de los componentes del grupo humano, que se puede considerar relacionado con el ambiente de los museos y monumentos, pertenezcan al sector de los clientes o al de los profesionales. No he utilizado la expresión aclarar o dar luz porque ya, en la definición dicha, puede surgir el primer problema espinoso: ¿es Patrimonio Nacional o son bienes del Estado?

La verdad es que Nación y Estado no parecen ser la misma cosa pero a la mayoría que no somos juristas ni políticos, creo que no nos merece la pena entrar en más honduras. Pero desde el punto 
de vista de los interesados en asuntos culturales, conviene que siga exponiendo aspectos generales del Patrimonio Nacional, puesto que ayudan a entender un poco los llamados museos y monumentos, que éste gestiona.

A lo largo de la historia, los Reyes han ido acumulando una serie de bienes muebles e inmuebles para su uso más o menos personal. La distinción entre hacienda real, hacienda pública y hacienda personal, no ha sido nunca excesivamente clara en lo que, genéricamente, se llama Antiguo Régimen. Los Palacios y Residencias Reales han contado, desde siempre, con los elementos de mobiliario necesarios para hacerlos habitables, $y$, además, conferirles ese aspecto de prestigio que significa la sede del poder. En los tiempos medievales, cuando la Corte era itinerante, largas recuas de animales precedían a la comitiva regia cargadas con arcas, cofres y baúles, conteniendo tapices, alfombras, pinturas, joyas u otro tipo de mobiliario que habían de servir a la adecuación del palacio de turno, fuera Valladolid, Burgos o Alfaro, Zaragoza, Huesca o Valencia, Pamplona u Olite: Y ya entonces tenemos noticias del afán de las Personas Reales, fueran de la Casa de Aragón, de la de Navarra o de la de Castilla, por rodearse de comodidades, de objetos bellos y valiosos, de atesorar riquezas y curiosidades, en fin, de practicar lo que luego se llamará coleccionismo. Nos podemos hacer una idea de todo ello repasando las cuentas de Sancho el Bravo, de Juan I o Jaime II, las del castillo de Olite, el testamento de Pedro el Cruel o tantos otros documentos. Se advierte cómo hay castillos que suelen estar dispuestos casi siempre y en los que, además, se guarda el tesoro, y otros que son residencias eventuales a las que hay que añadir revestimientos especiales si han de utilizarse. Igualmente, se observa cómo entre el personal al servicio de Rey, se encuentran constructores, pintores, tejedores u orfebres.

La estructura política no presenta una clara distinción entre lo que es patrimonio personal del Rey y lo que es patrimonio de la Corona. El Rey parece disponer con relativa libertad de uno y otro, de forma que son corrientes lo que hoy llamaríamos transferencias entre lo que nosotros consideraríamos bienes del Estado, bienes de la Corona o bienes privados y viceversa. Así que las pinturas, tapices, alhajas, y otros objetos, pueden sustraerse a las colecciones como pago de deudas, en testamentarías, etc. Es Felipe II quien iniciará, tímidamente, una vinculación de algunos de estos bienes en la persona del heredero de la Corona: pinturas, tapices, armas, ciertas joyas y muebles. Esta fórmula será seguida por sus sucesores, haciéndola extensiva Carlos II a todo lo que adornase las Residencias Reales; 
la citada disposición perduró con el espíritu del siglo XIX, a pesar de ciertas disposiciones de Carlos III y Fernando VII que contribuyeron a su dispersión.

No sería, precisamente, hasta el Reinado de Fernando VII, cuando se estableciese clara distinción entre el Patrimonio Real y el del Estado. Tal es el origen del Patrimonio de la Corona que, con diversos nombres, del Rey, Nacional o de la República, queda sancionado en la práctica, desde que, tras el trienio liberal, se establezca, claramente, una administración y un tratamiento distintos de los bienes al servicio del Rey, en cuanto tal, y de los que éste adquiere patrimonialmente, como cualquier otro particular. Los unos imprescriptibles e inalienables, los otros sujetos al derecho común.

Por ello, ateniéndose a las decoraciones palaciegas, las Colecciones Reales parecen arrancar, precisamente, del siglo XVII, si no se tiene en cuenta otro tipo de dotaciones, las religiosas, en las que los bienes quedaron vinculados desde siempre. Así sucedió en ciertas fundaciones eclesiales como la capilla de los Reyes de Toledo, la capilla Real de Sevilla y, en fin, ciertos Monasterios: entre ellos, y ante todo, el de San Lorenzo de El Escorial, magníficamente engalanado por Felipe II y al que añadieron preseas sus sucesores. A través de estas fundaciones es como mejor se puede forjar una idea de los bienes anteriores al siglo XVII. Pues junto a ese Patrimonio, y bajo la misma administración, hay una serie de conventos y otras fundaciones pías o benéficas, de las que el Rey es el Patrón fundamental, porque a él se deben los caudales para la creación y erección, o porque el fundador así lo expresó en su días. Son los Patronatos Reales.

Por otro lado, desde la Ilustración y las Luces de la segunda mitad del siglo XVIII, se asiste a un intento de que cierta parte de las Colecciones Reales sirvan a fines didácticos y públicos. Así nacerá el Museo del Prado. La creación de un Museo de Pintura y Escultura surge en tiempos de Carlos IV, aunque no se plasmará hasta la época de Fernando VII, desgajándose del Patrimonio Real en la Revolución de 1868. Carlos III ya había creado el Gabinete de Ciencias Naturales, embrión de lo que luego serán el Museo de Ciencias y el Museo Arqueológico Nacional, y más tarde surgirán el Museo de Artillería y el desaparecido Gabinete Topográfico. Como la nueva finalidad parece incompatible con la dedicación al uso regio, se buscarán locales separados de las moradas reales, de modo que el público no incomode las actividades palaciegas o administrativas. Por ello fue relativamente fácil sustraer alguna de tales colecciones de la administración de la Corona y colocarla bajo la dependencia de otro organismo del 
Estado, en ocasiones, y que ulteriormente no fuera reclamado. A pesar de los diversos desgajamientos, los fondos de las Colecciones Reales siguen siendo espléndidos, puesto que, al fin y al cabo, lo destinado a museos, en su día, no dejaba de ser lo considerado entonces como superfluo o fuera de uso, aunque fuese lo más bello, ya se tratase de los ticianos, las piedras duras chinas o las esculturas clásicas. Todo ello de mayor utilidad para el estudio o contemplación, que para ambientar el vivir privado o el ceremonial de la Casa Real. Los elementos necesarios para esto último siguen adecuando los diversos Palacios.

Lo mismo que sucede en el trazado y construcción de los edificios, al realizar su decoración se suele recurrir a los artistas de más prestigio del momento, sean pintores o escultores, orfebres, adornistas o ebanistas, muchos de lós cuales llevaran el título del Rey o de Cámara. Con ello, los Sitios Reales presentan, todavía hoy, una visión panorámica de la Historia del Arte, de las formas, del gusto y de la decoración, al menos a partir del manierismo renacentista y hasta el historicismo y eclecticismo de hace setenta años, en las más variadas manifestaciones, desde las artes del fuego hasta las del dibujo. La aludida historia del gusto nos puede mostrar, también, cómo en casi todos los tiempos ha existido un fuerte dirigismo cortesano en la interpretación de las formas, imponiendo moda en general, aunque ciertos artistas hayan escapado a su dictado. $\mathrm{Y}$ ese dirigismo está en íntima relación con toda una serie de industrias del lujo que se crean a partir del siglo XVIII, sobre todo, con el patrocinio de los Monarcas. Obedecen, por un lado, a mantener determinadas corrientes artísticas, por otro, a ser proveedoras de las fuertes demandas para engalanar los Sitios Reales, pero también a motivaciones económicas que estimulen la producción nacional frente a la competencia externa, suponiendo ahorro, y que orienten el gusto de las capas acomodadas de la sociedad en un determinado sentido. Son las Reales Fabricas. Entre ellas destacarán la de la Granja, con producción desde acristalamientos y espejos hasta lámparas y vajilla; la de Tapices de Santa Bárbara en Madrid, productora de series de tapices y alfombras para vestir paramentos, suelos e incluso techos; la de porcelana del Buen Retiro; la Platería de Martínez; y la relojería de Charost. Pero no son las únicas. Luego están los Talleres Reales. Además de escultura o bordado, existen los talleres de armería y ebanistería, y en las Fabricas Reales se llegan a crear otros de piedras duras, talla de marfil, bronce, etc. Todavía, visitando las Casas de campo de El Pardo, El Escorial o Aranjuez puede observarse una magnífica muestra de ello. 
Desde las Constituyentes de Cádiz hasta nuestro tiempo, se han dictado numerosas disposiciones con varios sentidos y efectos, de los que me interesa destacar, sobre todo, el paulatino desmembramiento y desafectación de muchos de tales bienes. La Ley de diciembre de 1869 hacía desaparecer del Patrimonio, el Museo del Prado, el Buen Retiro, La Florida y los Palacios de Granada, Valladolid, Barcelona y Valencia que ya no volverían a él, así como la Armería y los Patronatos. Los dos últimos se reintegrarían con la Ley de junio de 1876, tras la Restauración. Pocos años después, se segregarían la iglesia de San Jerónimo, los terrenos cedidos para la futura Catedral de Madrid, y, más adelante, en tiempos de la Segunda República, la iglesia de Montserrat, el Alcázar de Sevilla o la Casa de Campo. Fue desde entonces, y por la ley de marzo de 1932 que crea el Patrimonio de la República, cuando tales bienes se van a administrar por un Consejo con autonomía: esta situación persiste hasta nuestros tiempos con las leyes de 1940 y la actual de 1982. Sobre el citado sistema administrativo conviene hacer una breve exposición. El que gobierna, administra y gestiona tales bienes es un Consejo de Administración compuesto por un Presidente, como máxima autoridad, un Gerente que, por delegación, es el jefe del personal y puede disponer gastos y ordenar pagos, diez vocales y un secretario. Entre las competencias que le asigna la Ley, están la conservación, mejora y defensa de los bienes, y la promoción y cumplimiento de los fines de carácter científico, cultural y docente señalados en el artículo tercero.

La preocupación por la conservación de los bienes de interés histórico o artístico aflora ya en la Ley de diciembre de 1869, que se consolida en la de 1932, siendo en esta fecha la primera vez que se habla de Museos en cuanto destino de ciertos bienes. El mismo sentir se repetirá en las leyes de 1940 y 1982. Pero como tales bienes tienen otra función primordial, el Consejo de Administración dispone de una infraestructura, un tanto compleja, para poder abarcar las diversas funciones obligadas. El organigrama se reparte entre la Secretaría General y varias Direcciones. Entre las competencias de la primera, está la gestión de personal y medios económico-financieros. Una Dirección se ocupa de los Actos Oficiales y Mantenimiento, es decir, de la utilización de los Palacios por su Majestad, Familia Real y personalidades extranjeras. La Dirección de Patrimonio Arquitectónico e Inmuebles, incluye la conservación y restauración de los edificios, y la administración de sus productos. De la Dirección de Medios y Seguridad dependen ésta última y los medios informáticos. Finalmente, La Dirección que más nos interesa, es la del control y cuidado de los Bienes Muebles Históricos 
y Artísticos. Entre las competencias que ejerce la Vocalía Asesora de Programas Culturales, se integran las correspondientes a la difusión y a la Proyección Externa, entre las cuales se engloba la documentación y las actividades de promoción cultural, publicaciones, control de museos y exposiciones.

En ciertos Sitios, por su importancia y volumen de actividad, existe la figura del Delegado, a las órdenes directas de Presidencia y Gerencia, que coordina las actividades que se realizan en ellos, además de ser el jefe administrativo. Pueden depender de él más de un lugar.

Como suele suceder, esta complejidad administrativa y división de funciones conlleva, a veces, problemas de coordinación solucionables a nivel de Presidencia o Gerencia. Pues no parece fácil conjugar actividades tan dispares como la conservación de edificios o mobiliario -y la restauración-, con la seguridad y con su disponibilidad para el uso común, por decirlo de alguna manera. Pues, si algo es nota peculiar y distintiva de nuestras colecciones y edificios, es que se siguen destinando, en buena parte, para los usos para los que se concibieron $\mathrm{u}$ otros similares. Antes que colecciones y cámaras de tesoros raros, son residencias o conventos. Con ello se apartan un tanto del concepto habitual y corriente de museo, sea el viejo o el nuevo, y se aproximan más al de museo del futuro o museo vivo. No vivo porque en él, incidentalmente, se programen ciertas actividades con participación de los posibles clientes, sino vivo, en su más amplia acepción, al servir, cuando procede, como ámbitos para vivir, celebrar fiestas o recepciones y desarrollar actividades monásticas.

El Palacio Real de Madrid sigue siendo emblema del poder. En él se realizan ciertos actos culturales con la presencia de SS. ${ }^{\circ} \mathrm{MM}$., pero también posee un carácter institucional y representativo, recibiendo a Jefes de Estado o de Gobierno de otros países y a representaciones diplomáticas, como la presentación de cartas credenciales. Asimismo se preparan almuerzos y cenas de gala, se ofrecen recepciones al cuerpo diplomático, y S.M. el Rey celebra audiencias con militares, políticos, deportistas o profesionales de las artes y las letras. También tienen lugar ciertos fastos militares, como es la vistosa parada mensual con motivo del relevo solemne de la guardia. Todos los actos citados hacen que Palacio permanezca cerrado a la visita pública varios días al mes.

Aunque no con tanta frecuencia, también otros Reales Sitios se utilizan, eventualmente, con fines institucionales. Reuniones, conferencias, cumbres políticas internacionales, actividades congresuales, eventuales visitas reales, amén de conciertos y otras manifestaciones culturales pueden tener lugar en Aranjuez, en San Ildefonso, y en El 
Escorial. El Pardo suele estar habitado por personalidades extranjeras en diversas ocasiones, porque es el lugar dedicado a Residencia de Jefes de Estado o de Gobierno, que nos visitan, y a su séquito. Otro tanto sucede con los diversos Monasterios Reales ya que, aparte de la vida conventual de la comunidad, en ellos pueden realizarse solemnes celebraciones litúrgicas como, por ejemplo, exequias de la Familia Real.

Piezas raras de orfebrería y ricos ornamentos bordados siguen sirviendo para celebraciones litúrgicas, como son los preciosos tapices de las series del siglo XVI, o los más humildes recipientes de tocados decimonónicos de Falcó, Valdemorillo, y Pickmann de Sevilla. De ahí la existencia de ciertos «museos», un tanto entre comillas, en varios Sitios: la vida en Palacio, en Aranjuez; el Museo de Telas Medievales, en Las Huelgas de Burgos; el Museo de Tapices, en el Palacio de La Granja; o el Museo de la Caza, en Riofrío. En ciertos momentos ha parecido oportuno, por muy diversos motivos, consolidar como objetos museables piezas de diversas colecciones con la finalidad de que pudieran ser contempladas por el público. Agrupados temáticamente y suponiendo que no van a volver a ser utilizados, han ocupado determinados espacios y se han configurado como museos, lo que en nuestro sentido actual de los mismos, no pasarían de ser Colecciones especializadas, pues no cumplen, en rigor, todos los requisitos que señala el ICOM y recoge nuestra legislación. Esta es otra nota de las colecciones de Patrimonio Nacional: el Museo dentro del Museo. En otro momento, el Consejo de Administración ha podido reconsiderar la posible vigencia de uso de algunas de tales piezas, y el citado museo se ha visto desprovisto de ellas al destinarse a otro fin de uso habitual, en lugar de permanecer como muestras en la exposición de turno.

Pero quizás yo considere como la característica más interesante, lo que podríamos llamar museo integral, al menos hasta cierto punto, y que se deriva un poco del aspecto de museos vivos a que aludía antes. Muchos de ellos, precisamente por esa peculiaridad de utilización, se componen de una serie de factores que agrupan las más diversas tipologías de Museos. Se trata de Sitios con sus campos y jardines que pueden considerarse históricos y apreciarse como paisaje o jardín botánico; en ellos se alzan uno o más edificios palaciales, en parte, al menos, preparados para vivirlos, y con una serie de elementos de mobiliario o unos ambientes interiores que permiten considerarlo monumento arquitectónico, museo de historia, museo de artes decorativas, etc. 
Hagamos una enumeración de ellos:

* En Madrid el Palacio Real con su jardín o Parque del Campo del Moro.

El Monte y el Palacio de El Pardo con la Casita del Príncipe, el Palacio de la Zarzuela, residencia de SS.MM., y el Palacio de La Quinta con sus jardines, además de la iglesia del Carmen y el convento de capuchinos del Santo Cristo.

* En Aranjuez el Palacio Real y la Casita del Labrador con sus jardines y edificios anexos entre los que se halla el llamado Museo de Falúas y la iglesia de San Antonio.

* En San Lorenzo de El Escorial, el Palacio Real dentro del Monasterio con sus edificios anexos, casas de oficios de la Reina y de Infantes, además de los palacetes llamados de las Casita del Príncipe o de Abajo y del Intante o de Arriba.

* En Segovia, los Palacios de San Ildefonso y de Riofrío y sus edificios anexos con los jardines y bosques que los rodean.

* En Palma de Mallorca, el Palacio Real de La Almudaina con sus jardines.

Además ejerce los derechos de patronato o de gobierno sobre las siguientes fundaciones:

* Iglesias y Conventos o Monasterios de la Encarnación, Santa Isabel, Descalzas Reales, Basílica de Atocha y Panteón de Hombres Ilustres, iglesia y hospital de Buen Suceso, iglesia y colegio de Loreto, de Madrid.

* El Monasterio de San Lorenzo el Real de El Escorial

* El Convento de San Pascual en Aranjuez,

* El Monasterio de Santa Clara de Tordesillas (Valladolid)

* El Monasterio de Las Huelgas con sus anejos y el Hospital del Rey, en Burgos.

* El Colegio de Doncellas Nobles de Toledo, éste en copatronato con el Arzobispo de Toledo.

Conviene señalar cómo este Patrimonio Nacional es un ente de Derecho Público distinto a lo que se denomina Patrimonio del Estado y Patrimonio Histórico Español, aunque sea aplicable por defecto la legislación por la que éstos se rigen. El primero es una cuestión del Ministerio de Hacienda, el segundo del de Educación y Cultura, mientras Patrimonio Nacional suele estar vinculado a la Presidencia del Gobierno.

A través de las páginas que siguen, el lector puede hacerse una idea de la riqueza ya apuntada, en lo que se refiere a las dos Colecciones quizá más insignes: armas y tapices. También de otras de menor entidad relativa, unas algo afamadas, como las de pintura, carruajes y gua- 
darnés, otras más desconocidas, como los textiles o la escultura. Pero todas éstas, al menos porcentualmente, no significan más allá de una cuarta parte de lo que conserva Patrimonio Nacional.

El inventario informatizado, que se llevó a cabo recientemente, registra más de ciento cincuenta mil piezas repartidas en treinta y nueve colecciones que abarcan desde los juguetes, instrumentos científicos, porcelana u orfebrería, hasta los ornamentos litúrgicos o muebles. La clasificación, como todas, es un tanto cuestionable, pues en unos casos se basa en la materia, en otros en la función, y a veces se ha atendido a la tradición. Pero es útil para lo que se pretende. La cuestión es que vienen a ser un repertorio muy extenso, aunque sea incompleto, de lo que se ha dado en llamar Artes Decorativas, por lo que no está de más dar aquí una brevísima idea de las mismas.

De entre las artes del fuego, la primera es la cerámica, capaz de transformar el barro en toda suerte de recipientes. Aparte de ciertos restos arqueológicos y de las hermosas tinajas estampilladas del siglo XV del Colegio de Doncellas Nobles de Toledo, las series se inician con la producción talaverana de azulejería que revisten diversos elementos, horizontales y verticales, en dependencias de El Escorial y en Descalzas, desde el último tercio del siglo XVI, y que a comienzos del siguiente siglo se usarán también en Encarnación o Huelgas de Burgos. En ellas se aprecia la renovación de las formas decorativas tradicionales por influjo de los Países Bajos que, casi un siglo antes, los Reyes Católicos habían contribuido a difundir con los nuevos conceptos estilísticos en el alicatado, al confiar a Francisco Niculoso Pisano los retablos de los alcázares sevillanos. Queda, todavía, alguna rara muestra de recipiente talaverano con recuerdos de Delft, y también de aquellos búcaros mejicanos, extremeños o portugueses que servían de golosinas a las damas de la Corte en el siglo XVII, según cuenta Madame D'Aulnoy.

En el siglo XVIII el grueso de la colección lo forman piezas de porcelana, ese raro invento chino del que sólo a comienzos de la mencionada centuria se alcanza su secreto en Europa. Sabemos que Felipe II contaba con bastantes ejemplares, que en su tiempo podían venir a través del Indico a Lisboa, o desde Filipinas atravesando el Pacífico por la ruta de Acapulco. Pero lo más antiguo conservado corresponde a Felipe V, incluida alguna imitación en loza de Alcora. Carlos III conseguirá otras piezas gracias a la Compañía de Filipinas, entre ellas muchos de los magníficos tibores que adornan los Reales Palacios. Es Carlos III quien creará, primero en Nápoles, y trasladará luego a Madrid, una manufactura de porcelana, probablemente intentando emu- 
lar la de su suegro en Meissen, e incluso la de Berlín, de la que aún se conservan bastantes piezas de vajilla, lámparas o figuritas, mientras que de la factoría madrileña de Buen Retiro son muy pocas. Pero hay dos conjuntos de gran belleza como las Salas de Porcelana de Aranjuez y Madrid, la una chinesca todavía, la otra en rococó europeo a pesar de distanciarse solo tres años en el tiempo. Para Carlos IV, o a iniciativa suya, se crearán en el Retiro hermosos y gigantescos vasos, o las magníficas placas a imitación de Wedgwood que revisten la habitación de la Casa del Príncipe en El Escorial. Pero lo más importante de lo existente en vajilla (la de Carlos y Luisa) será de Sévres o París, como también la de su hijo Fernando VII (vajilla de paisajes, juegos de té o café de camafeos o del amor materno), aunque no falten algunas berlinesas (plantas medicinales), y asimismo de la nieta Isabel II (vajilla de gala, de castillos y leones), e incluso, de Alfonso XIII, a pesar de que en su Reinado las más significativas son inglesas. Las piezas de Moncloa son raras aunque no faltan las esculturitas, de las que hay también francesas (Nast, Jacob Petit), alemanas y danesas en el XIX, siglo en el que, aunque no sea lo más fino, cabe destacar la producción de lozas blancas o finas, idea inglesa de finales del siglo XVIII para sustituir en barato a la porcelana, implantándose a este efecto, diversas manufacturas en España. Representación hay de Sargadelos, de Moncloa, de Iberotanagra de Santander y muy abundantes y bellas las de Pickmann de Sevilla.

A la colección de cerámica, sigue en número de objetos la de cristal. Aparte de alguna pequeña ampolla romana o medieval, se inicia con la producción de la Real Fábrica de La Granja, fundada por Felipe V, y apoyada por los distintos Soberanos hasta Fernando VII, de la que, sin embargo, no hay excesiva representación si lo comparamos con el conjunto de la Colección. Prescindiendo de los efectos de botica, aún pueden contemplarse en los Reales Sitios varias arañas; algunas cornucopias figuradas a la rueda y a la arena, incluido un vigoroso retrato de Carlos III; y también cierta cantidad de vajilla correspondiente a los diversos Reinados desde Fernando VI, alguno de gran porte, como la ponchera con paisajes o el gran vaso de personajes, y otros de enorme delicadeza como los vasos con escenas firmadas y fechadas alrededor de 1830, o la cristalería de las Virtudes, que probablemente es de importación, pero no su grabado, que habrá sido realizado en la Manufactura Real. Demasiado poco para lo que hubo. La bella cristalería de caramelos de Fernando VII, en cristal doblado, es probablemente francesa, como lo serán las de gala de Isabel II y de Francisco de Asís, de Baccarat y de Sévres, respectivamente, aunque también fueron 
El Patrimonio Nacional. Museos vividos

clientes de Badalona y Gijón. De esta última, la fábrica de La Industria, de Pola y compañía, suministrará una elegante cristalería a Alfonso XII, y, en 1931, la Unión Vidriera de Badalona, otra a Alfonso XIII. Pero los más finos conjuntos a partir de la Restauración serán bohemios, como el juego de té de doña Cristina, o las cristalerías Alphonse y Copenhagen, suministradas por Moser a Alfonso XIII. La brevedad de espacio impide relacionar otras piezas, como algunas preciosidades en cristal doblado y tallado de Bohemia, de los siglos XVIII y XIX, los productos de Val Saint Lambert o las piezas inglesas.

De los factores que más sirven para prestigiar el poder son la riqueza y la magnificencia, que se reflejan como de ninguna otra manera en los metales nobles de la orfebrería. Por ello no es de extrañar que sea Colección abundante, teniendo en cuenta, además, que muchas de sus piezas son repetitivas. Mucho más lo sería si la propia naturaleza de los componentes no hubiese facilitado su transformación en moneda líquida ante necesidades urgentes. Por ello, se apuntaba antes, cómo lo más antiguo ha de verse en los Patronatos, pues la mayor parte de lo conservado en los Palacios responde al siglo XIX. Como en otras Colecciones, algún raro ejemplar subsiste de la Antigüedad (tesoro de Guarrazar), o de la plena Edad Media (cruz de las Navas de Tolosa en las Huelgas), pero una seriación cronológica no puede establecerse sino desde el fin del gótico con unas cuantas alhajas mallorquinas y burgalesas de uso religioso, como suelen serlo las del renacimiento y manierismo, aunque no falten objetos de uso civil. Es interesante recalcar que corresponden a muy diversas platerías nacionales, germánicas o italianas, destacando las arquetas de Wenzel Jamnitzer, o la regalada por el Duque de Saboya a Isabel Clara Eugenia. Lo propio ocurre con las piezas de tipo clasicista o barroco del siglo XVIII, entre las que sobresale el magnífico cuadro romano de la Detención de Atila sobre modelo de Algardi. Extraña la ausencia de productos de las Indias, representados, tan sólo, por un cáliz mejicano de hacia 1689 y alguna piezas más tardía; asimismo asombra la presencia del cetro ruso.

A partir del siglo XVIII, el número de piezas de uso civil aumenta, transformándose en mayoría en el XIX. Todavía hay representación de platerías diversas nacionales (Toledo, Córdoba, Sevilla, Valencia, Zaragoza y varias más) e italianas (Roma, Nápoles, Palermo), y algún raro espécimen francés o inglés, pero ahora la inmensa mayoría es de producción madrileña con nombres tan representativos como Serrano, Medrano, Velasco, Farquet, Giardoni, los Elvira, los Urquiza, Ferroni o la Real Fábrica de Martínez, que muestran la evolución del vocabulario 
formal, desde el barroco tradicional español al neoclasicismo, pasando por las diversas tendencias de lo rococó.

Tras la guerra de la Independencia, prosigue el predominio de la platería madrileña con pervivencia de las formas neoclásicas y de los tradicionales suministradores, Urquiza o Real Fábrica, a los que se unen nombres nuevos como Marschal, Perate o Macazaga, con piezas tan notables como los juegos de bautizar o de tocador. Pero a partir del Reinado de Isabel II, las piezas de origen madrileño, como el ornamento de Colón de Marquina Espuñes, o las de Arellano y Sellán, se codearán con las catalanas del varias veces laureado Isaura o Carreras y las francesas, entre las que destacan, sobre todo, los productos de Froment Meurice. Todo ello utiliza el vocabulario historicista del eclecticismo, como sucederá con los trabajos del platero de Alfonso XII, Francisco Marzo, y llegará a tiempos de Alfonso XIII, sean de origen nacional, francés o inglés. Buen ejemplo de ello es el teléfono diseñado por Pola, en buena parte de metal plateado, material que se impone desde el último tercio del siglo XIX y del que, junto a ejemplares de origen inglés o francés, pueden contemplarse otros de Meneses.

Proximidad a la orfebrería tienen otras artes del metal, siendo las más cercanas la de los latoneros, caldereros y fundidores de bronce, profesión esta última que suele ir ligada al platero, y de la que ejemplos como Ferroni o Urquiza, en el tránsito de los siglos XVIII a XIX, resultan bien elocuentes. La Colección es rica y amplia y abarca desde braseros del siglo XVI, a las magníficas piezas luminarias o de adorno fabricadas por la casa Thomire para Carlos IV, Fernando VII e Isabel II, pasando por los hacheros o tenebrarios de factura flamenca en las -Descalzas Reales.

También es importante, y acaso más que los objetos ya citados, aunque menos abundante, la Colección de relicarios entre los que contamos con buenos ejemplos de esa dedicación del orfebre al trabajo en otros metales, como son los bustos y pirámides relicario elaborados por Juan de Arfe y Lesmes Fernández del Moral para San Loręnzo El Real de El Escorial. Tal Colección recoge, esencialmente, contenedores o recipientes de las más variadas formas y elaborados con las más diversas técnicas artísticas. Felipe II buscó, y consiguió, un gran número de reliquias procedentes de Alemania, Italia, Países Bajos, Francia, Inglaterra y la misma España, y para ellas encargará los aludidos relicarios, pues no todos venían con recipientes adecuados. En bastantes casos, sin embargo, los tenían. Así el lote de huesos contrahechos en oro y plata dorada a comienzos del siglo XIV, por orfebres al servicio de Wenceslao III de Bohemia, de brevísimo reinado, están dotados de 
magnífica esmaltería; la arquilla de hueso de Paderborn, cuya bárbara iconografía la ha hecho suponer obra del siglo $\mathrm{X}$, aunque debe ser más tardía; o la hermosa arqueta en forma de iglesia, soberbio ejemplo de la ataujía milanesa en el siglo XVI. Tanto en los diversos Monasterios como en la Real Capilla hay abundancia de ellos, lo mismo de los más ricos como de aquellos otros más modestos que se suelen considerar obra monjil por ser sus componentes más visibles, labores de aguja.

Con la aguja tienen que ver también los ornamentos litúrgicos, de los que hay magníficos ejemplos en El Escorial, producto no exclusivamente del obrador que allí instalara Felipe II, y para el que realizarán modelos dibujados Barroso o López de Escuriaz que, afortunadamente, se conservan en parte. Fuera de ellos, pueden verse varias piezas importantes en los diversos Monasterios, desde el siglo XVI con secuencia hasta la producción decimonónica del taller toledano de Molero. Aunque sea a borbotón, no pueden menos de citarse, a propósito de la puntada del siglo XVI, las piezas orientales, los emplumados novohispanos o los reposteros de Las Huelgas.

En relación con los metales no hay que olvidar la relojería, pero en este caso la labor del broncista y del orfebre, con ser importante, queda en segundo plano respecto a la ciencia aplicada que suponen los conocimientos matemáticos pertinentes para producir la máquina de las horas con su adecuada precisión. Tanto los Austrias como los. Borbones fueron grandes amantes de la relojería, pero apenas nos queda nada de los primeros, si exceptuamos el Candil elaborado por Hans de Evalo para Felipe II. En cambio son relativamente numerosos los ejemplares Borbónicos, más de seiscientos, aunque quizá no alcancen a una décima parte de los que poseyeron realmente. En tiempos de Felipe V se crearía la Escuela-Fábrica de Relojería de San Bernardino, precedente de la establecida y dirigida, en tiempos de Carlos III, por los hermanos Charost. Y tanto este Rey, como antes su hermano Fernando VI y luego su hijo Carlos IV, pensionarían a diversos individuos para perfeccionar sus técnicas en Inglaterra, Francia o Suiza. De tiempos de Felipe $\mathrm{V}$ son algunos bracket y relojes de caja alta londinenses de Quart y Ellicot, destacando el astronómico de torre de Hildeyard, que hubo de ser reparado en tiempos de Fernando VI, al que corresponden, por otro lado, varias piezas de Jaquet-Droz. La más famosa pieza de este artista, es, acaso el llamado del Pastor por el autómata músico que lo corona. Es en tiempos de Carlos III, y sobre todo de Carlos IV, cuando más relojes se compran para decorar los Reales Palacios, con ejemplares tan caprichosos como el de Pierre Le Roy adornado con figuritas de porcelana, el regulador de caja alta de Berthoud, 
los varios de Godon entre los que destaca el de Cronos de monumental caja realizada en la Real Fábrica del Retiro, el de la Columna de Trajano de Bourdier, o las realizaciones de diversos españoles como Manuel Gutiérrez (esqueleto), Manuel de Rivas o Antonio Molina. Al final del período corresponderán los hermosos planetarios de Breguet y Raingo. A partir del Reinado de Fernando VII se consolidará la adquisición de relojería francesa que ahora será más atractiva por su contenedor, con magníficos bronces, esmaltes y cristales tallados que, por su mecanismo, ha llegado a su más alto grado de desarrollo.

En líneas generales otras dos Colecciones muy importantes son paralelas a la de relojería en cuanto a contenido: muebles y abanicos. Creo que ambas merecerían un comentario más extenso, pero baste ahora con decir que la primera nos presenta raros pero exquisitos ejemplos de la labor de madera desde comienzos del siglo XVI y que, sólo a partir del Reinado de Felipe V, menudean los ejemplares mostrando las más diversas tendencias italianas, francesas, incluso inglesas, en lo tardobarroco y rococó, llegando a una exquisitez difícilmente superable al final del Reinado de Carlos III y en el de Carlos IV, mientras adquieren una especie de pesadez o monotonía en tiempos de Fernando VII, una vez alcanzado el virtuosismo técnico, sin que por ello dejen de presentarse magníficas labores en la marquetería o en la aplicación de materiales como el vidrio o la porcelana.

De muchas otras se podría hablar con mayor o menor propiedad, así juguetes o instrumentos científicos, pero, al menos, se ha dado somera razón de las más importantes en cuanto a número, calidad y relevancia dentro del Patrimonio Histórico Español. 